\title{
Secondary Predication and Aspectual Structure
}

\author{
Susan Rothstein \\ Bar-Ilan University \\ rothss@mail.biu.ac.il
}

\begin{abstract}
This paper presents an analysis of secondary predicates as aspectual modifiers and secondary predication as a summing operation which sums the denotation of the matrix verb and the secondary predicate. I argue that, as opposed to the summing peration involved in simple conjunction, there is a constraint on secondary predication; in the o case of depictives, the event introduced by the matrix verb must be PART-OF the event introduced by the secondary predicate, where $e_{1}$ is PART-OF $e_{2}$ if the running time of $e_{1}$ is contained in the running time of $\mathrm{e}_{2}$, and if $\mathrm{e}_{1}$ and $\mathrm{e}_{2}$ share a grammatical argument. I argue resultative predication differs from depictive predication in that the PART-OF constraint holds in resultative constructions between the event which is the culmination of $e_{1}$ and $e_{2}$ : formally, while depictive predication introduces the statement PART-OF $\left(\mathrm{e}_{1}, \mathrm{e}_{2}\right)$, resultative predication introduces the statement PART-OF(cul $\left.\left(\mathrm{e}_{1}\right), \mathrm{e}_{2}\right)$. I show that this is all that is necessary to explain the well-known properties of resultative predication.
\end{abstract}

\section{Introduction}

This paper presents a discussion of the semantic function of secondary predication. I argue that secondary predicates are aspectual modifiers in the sense that they introduce a new event and define a relation between it and the event introduced by the main predicate. I consider this aspectual modification since it presents the main event in the context of its relation with another event, and this may have the effect of explicitly changing the aspectual character of the matrix, or main, event. I begin by presenting some of the properties of secondary predication which any account has to explain. I go on to distinguish explicitly between secondary predicates and nominal modifiers, on the one hand, and between secondary predicates and adverbials on the other, and I argue that secondary predicates are related to the matrix eventuality via a relation of event summing, which is essentially the same as the summing operation which Lasersohn (1992) argues is the core of the conjunction relation. In the second part of the paper, I show that there are constraints on the secondary predication relation; specifically, there is a temporal 'part-of' relation and a constraint that the matrix verb and secondary predicate share a grammatical argument, and I show how this explains some of the most characteristic properties of both depictive and resultative predication. Although this paper is self-contained, it is part of a bigger project on the nature of incrementality and the structure of accomplishments, and space constraints mean that I won't be able to go into all the detail that I'd like.

The basic data that we have to deal with are as follows:

(1) a. John painted the house red $_{\mathrm{i}}$.

b. Mary drank the coffee ${ }_{i}$ hot $_{i}$.

(2) $\mathrm{John}_{\mathrm{i}}$ drove the car drunk $\mathrm{i}_{\mathbf{i}}$

The examples in (1) are object-oriented predicates. (1a) is a resultative: the sentence means roughly "John painted the house and as a result the house was red, and (lb) is a depictive, and 
d. *What Mary did hot was drink the coffee.

e. What Mary did was paint the house red.

f. *What Mary did red was paint the house.

Second, secondary predicates may stack, as shown in (8):

(8) a. Bill $j_{j}\left[\left[\text { drove the } \text { car }_{j} \text { broken }_{i}\right]_{V^{\prime}} \text { drunk }_{j}\right]_{V P}$

b. Jane $\mathrm{j}_{\mathrm{j}}\left[\left[\text { painted the } \mathrm{car}_{\mathrm{i}} \text { red }_{\mathrm{i}}\right]_{\mathrm{V}} \text { ' } \text { drunk }_{\mathrm{j}}\right]_{\mathrm{VP}}$

c. ?Jane $_{j}\left[\left[\text { painted the car }{ }_{i} \text { red }_{i} \text { broken }_{i}\right]_{V^{\prime}} \text { drunk }_{j}\right]_{V P}$

d. ${ }^{*} J_{a n e} e_{j}\left[\left[\text { painted the } \text { car }_{i} \text { broken }_{i} \text { red }_{i}\right]_{V}{ }^{\prime} \text { drunk }_{j}\right]_{V P}$

Third, secondary predicates do not form a constituent with their subject. This is obvious for subject-oriented depictives, as the stranding facts in (7) show. It also holds for object-oriented predicates, and this can be shown via contrasts with small clause predicates. If an objectoriented predicate and its subject formed a constituent, then that constituent would be the direct object of the matrix verb, and this is exactly what happens with small clause predicates such as those in (9) (see Rothstein (in press) for a detailed discussion).

(9) a. Mary considers [John intelligent $]_{\mathrm{SC}}$

b. Mary made [it seem that John was on time $]_{S C}$

But in these constructions, the entailments are very different from those in secondary predicate constructions, as the following data show. (10a/11a) do not entail (10b/11b), while $(12 \mathrm{a} / 13 \mathrm{a} / 14 \mathrm{a})$ do entail the $\mathrm{b}$ examples, and the contrast between the examples in (15) demonstrate the same point.

(10) a. Mary believes/considers John foolish.

b. Mary believes/considers John

(11) a. Mary saw the president leave.

b. Mary saw the president.

(12) a. Mary drank her coffee hot.

b. Mary drank her coffee.

(13) a. Mary painted the house red.

b. Mary painted the house.

(14) a. Mary drove the car drunk.

b. Mary drove the car.

(15) a. \#Mary drank her coffee hot though she never drank her coffee.

b. John believes Bill a liar, and he doesn't believe Bill.

Fourth, secondary predicates are optional (and again the contrast is with small clause predicates): 
a. *I thought/believed that problem.

b. Mary drank her coffee/drove the car/painted the house.

Fifth, secondary predicates assign a thematic role to their arguments (subjects). There is no morphological difference between secondary predicates and small clause predicates and they are subject to the same structural condition on predication (see Rothstein, in press), and we assume that this indicates that in both constructions they have the same thematic properties. I assume also, following Higginbotham (1983), Parsons (1990), Kratzer (1995), Greenberg (1998) and Rothstein (1999, in press) that adjectival predicates introduce some kind of eventuality argument into the representation. (For simplicity, I will assume that this is an e variable, and not introduce the distinction between mass-eventualities denoted by adjectives and count eventualities denoted by verbs which I argue for in Rothstein (1999).)

Assuming, then a neo-Davidsonian framework in which verbs and adjectives denote sets of events, and thematic roles introduce functions from events to participants (Parsons 1990, Landman, in press), the predicate drunk, as it occurs in both (17a) and (17b) will translate as an expression like (18):

(17) a. I consider Mary drunk.

b. I met Mary drunk.

$$
\text { drunk: } \rightarrow \lambda \times \lambda e . D R U N K(e) \wedge \operatorname{Arg}(e)=x
$$

\section{What secondary predicates are not}

\subsection{Secondary Predicate are not nominal modifiers}

That secondary predicates are not nominal modifiers is shown through pronominalisation tests and through testing entailments. First, entailments. When an AP is used as a secondary predicate then the property that it expresses must hold of the denotation of its subject for the whole time that the matrix event is going on (for depictives) or for the whole time that the culmination of the matrix event is going on (for resultatives). With nominal modifiers this is not so.

(19) a. I met the drunk man again, but this time he was sober.

b. \#I met the man drunk again, but this time he was sober.

(20) a. The drunk man drove the car home, after he had sobered up.

b. \#The man drove the car drunk, after he had sobered up.

(21) a. They paint the red house once every year. Last year they painted it white and this year they painted it green.

b. \#They paint the house only once a year, and they always paint it red. Last year they painted it white and this year they painted it green.

Nominal modifiers are part of the NP combining with $\mathrm{N}$ to form a Common Noun expression, and they are not temporally related to the matrix verb at all. The fact that they are syntactically part of the nominal argument expression, while secondary predicates are not, is shown 
by the fact that pronominalisation replaces the expression containing the nominal modifier, while it does not affect the secondary predicate at all.

(22) a. I met the drunk man today $\rightarrow$ I met him today/*I met drunk him today.

b. I met the man drunk today $\rightarrow$ I met him drunk today.

\subsection{Secondary predicates are not adverbs}

We can show that secondary predicates are to be distinguished from adverbs again via comparing entailments. (23a) entails that John was drunk, (23b) is compatible with no-one being drunk. And as a correlate, as (24) shows, the secondary predicate, but not the adverb, needs a lexically expressed subject.

(23) a. John drove the car drunk.

a. \#John drove the car drunk, although he was sober.

b. John drove the car drunkenly.

b'. John drove the car drunkenly, although he was sober.

(24) a. The car went (drunkenly) round the corner (drunkenly).

b. \#The car went round the corner drunk.

I conclude that secondary predicates must be predicated of a subject, and that they assign a thematic role to that subject, whereas adverbs do not do so. If we make this the litmus test for distinguishing between adverbs and secondary predicates, then an obvious question is what about subject-oriented adverbs, such as enthusiastically or reluctantly, as illustrated in (25), which appear also to assign some sort of thematic role to the subject:

John greeted Mary enthusiastically/reluctantly.

But it seems to me that, although these adverbs are subject-oriented (or more properly, agentoriented), and must introduce a relation between the denotation of the subject and the event, this orientation is not equivalent to predication. The function of these adverbs is to add the information that the agent of the matrix verb performed the action in a certain way, i.e. in an enthusiastic or reluctant way, but they do not entail that this agent had the property of being himself enthusiastic or reluctant. Thus (26a) entails that John was reluctant about something, but not that he was enthusiastic about anything, and the converse is true of (26b). Similarly, (26c) is not a contradiction, and neither is (26d), where the AP is used as a secondary predicate:

(26) a. John greeted Mary enthusiatically, although he was secretly very reluctant to meet her.

b. John greeted Mary reluctantly, although he was secretly very enthusiastic about meeting her.

c. John welcomed Mary enthusiatically although he was not enthusiastic about welcoming her.

d. John greeted Mary drunkenly, although he did not, in fact, greet her drunk. 
intersection is not the right way to treat predicate conjunction; alternately entails that the instances of being hot and the instances of being cold are temporally distinguishable, and are thus distinguishable events. Since secondary predicates are not temporally modified or located independently of the main verb, this kind of evidence is not available for our structures. However, we can still argue that the event introduced by the matrix verb and the secondary predicate must be distinguished using the arguments from finegrainedness presented in Parsons (1990), from which it follows that the representation in (31) cannot be correct. Parsons argues that different event predicates which hold of an argument at the same run time can be modified by contradictory modifiers. So suppose with one stroke of the broom I sweep away both a pile of dirt and an earring, then it can be true that I intentionally swept away the pile of dirt and accidentally swept away an earring. But since an event cannot be both intentional and accidental at the same time, Parsons argues that the two expressions swept away the pile of dirt and swept away an earring must be descriptions of different sweeping events, distinguished by the fact that they have different participants, and which hold at the same time. We have just shown in the previous section that AP predicates, unlike adverbs, introduce thematic roles; this means that they denote entities which have participants, which means that they denote events which can be identified via their participants. So, while an event of driving is an event which must have two participants, an agent and a theme, an event of being drunk must have one participant, which we have called for convenience the experiencer, but which crucially is not an agent, and cannot be therefore 'borrowed' from the matrix verb. We can make the argument even stronger by looking at examples like (32) where the adjectival head of AP introduces two thematic roles:

John drove the car drunk from the cognac.

Here we can clearly distinguish the event introduced by drive, which has John as the agent and the car as the theme, and thus denotes an event with John and the car as participants, and the event introduced by drunk, which has John as its external argument and the cognac as the internal argument, and thus denotes an eventuality with John and the cognac as participants. At this point we can see that the two events belong to two aspectual classes too: JOHN DRIVE THE CAR is an activity while JOHN DRUNK ON THE COGNAC is a state. But if these are the appropriate distinctions to make, then the reading in (31), which asserts that there was one event of which both these predicates can be predicated, will just be false.

I therefore assume, following Lasersohn (1992), Krifka (1992, 1998), Landman (in press), that the domain of events has a part structure: i.e. it forms a Boolean semilattice, with the sum operation, $\sqcup$, and the part of relation, $\sqsubseteq$, defined in the usual way, such that $x \sqsubseteq y$ iff $\mathrm{x} \sqcup \mathrm{y}=\mathrm{y}$. Secondary predication will involve a generalised summing operation, which we can call 'S' (for summing) which sums the denotation of two event expressions to yield a singular event in the following way:

$$
\mathrm{S}\left(\alpha\left(\mathrm{e}_{1}\right), \beta\left(\mathrm{e}_{2}\right)\right)=\lambda \mathrm{e} \cdot \exists \mathrm{e}_{1} \exists \mathrm{e}_{2}\left[\mathrm{e}={ }^{\mathrm{S}}\left(\mathrm{e}_{1} \sqcup \mathrm{e}_{2}\right) \wedge \alpha\left(\mathrm{e}_{1}\right) \wedge \beta\left(\mathrm{e}_{2}\right)\right]
$$

This gives (34) as the translation of (30):

$$
\begin{aligned}
& \exists e \exists e_{1} \exists e_{2}\left[e=s\left(e_{1} \sqcup e_{2}\right) \wedge \operatorname{DROVE}\left(e_{1}\right) \wedge \operatorname{Ag}\left(e_{1}\right)=\operatorname{JOHN} \wedge \operatorname{Th}\left(e_{1}\right)=\operatorname{THE} C A R\right. \\
& \left.\wedge \operatorname{DRUNK}\left(e_{2}\right) \wedge \operatorname{Arg}_{1}\left(e_{2}\right)=J O H N\right]
\end{aligned}
$$


(34) is true if there is an event which has both an event of John driving the car as part and an event of John being drunk as a part.

\section{Constraints on the secondary predication operation}

I assume, then that (34) represents the basic machinery involved in introducing a secondary predicate into a sentence. However, as it stands it is clearly not enough. There are presumably constraints on the summing relation, otherwise secondary predication would not be distinguishable semantically from predication conjunction with and. Furthermore, there are a series of questions about the nature of secondary predication, and we would like the answers to fall out from the properties of the operation. Here is a list of some of the issues.

1. What are the constraints on the summing relation which distinguish secondary predication from event conjunction?

2. Why are there no intransitive depictives? i.e. why does "I sang the baby asleep" not have the reading "I sang while the baby was asleep"?

3. Why are the two kinds of secondary predicates depictive and resultative (e.g. why are there no 'inceptives')?

4. Why are resultatives not predicated of subjects?

5. What are the effects on aspectual class of adding a secondary predicate?

6. How can we account for the restricted set of examples discussed in Wechsler (1997) and Rappaport Hovav (1999) which are purported to be subject-oriented resultatives?

In what follows, I will give the outline of an analysis of the secondary predication relation which answers these questions, although the space limitations prevent me from giving a very detailed account. I'll start with a discussion of depictive secondary predication.

We begin with the crucial difference between secondary predication and event conjunction. As the contrast between $(35 \mathrm{a} / \mathrm{b})$ shows, there is a temporal dependence between the matrix event and the event introduced by the AP. I compare secondary predication with simple conjunction of VPs and conjunction in small clause complements so as to show that the difference does not follow from independent constraints that conjoined matrix sentential predicates must each be independently marked for tense. (The necessity for be in $(35 \mathrm{~b} / \mathrm{c}$ ) will be discussed below. Crucially, the be is untensed, and cannot introduce a temporal dependency.)

(35) a. Mary made John drive the car to Tel Aviv drunk.

b. Mary made John drive to Tel Aviv and be drunk.

c. Mary made John drive to Tel Aviv and John be drunk.

$(35 \mathrm{~b} / \mathrm{c})$ are true if Mary made there be a sum of events which had an event of John driving and an event of John being drunk as a parts, but there is no indication of a temporal relation between these events; the first can precede the second or vice versa, or the first can be contained in the second or vice versa, or one can overlap the other. However, in (35a), the event introduced by the verb must be temporally contained within the event introduced by the secondary predicate; in other words, the John must be drunk all the time that the event of his driving to Tel Aviv is going on. Assuming a temporal trace function ' $\tau$ ', which maps an event e onto its running time such that the $\tau\left(e_{1} \sqcup e_{2}\right)=\tau\left(e_{1}\right) \sqcup \tau\left(e_{2}\right)$ (the run time of the sum of $e_{1}$ and $e_{2}$ is the sum of the run time of $e_{1}$ and the run time of $e_{2}$, with sum defined as above), the summing operation which introduces a depictive secondary predicate must be as in (36): 


$$
S^{\mathrm{D}}\left(\alpha\left(\mathrm{e}_{1}\right), \beta\left(\mathrm{e}_{2}\right)\right)=\lambda \mathrm{e} \cdot \exists \mathrm{e}_{1} \exists \mathrm{e}_{2}\left[\mathrm{e}={ }^{\mathrm{s}}\left(\mathrm{e}_{1} \sqcup \mathrm{e}_{2}\right) \wedge \alpha\left(\mathrm{e}_{1}\right) \wedge \beta\left(\mathrm{e}_{2}\right) \wedge \alpha\left(\mathrm{e}_{1}\right) \subseteq \beta\left(\mathrm{e}_{2}\right)\right]
$$

This gives (37) as the translation of (30):

$$
\begin{aligned}
& \exists e \exists e_{1} \exists e_{2}\left[e^{\mathrm{S}}={ }^{\mathrm{s}}\left(\mathrm{e}_{1} \sqcup \mathrm{e}_{2}\right) \wedge \operatorname{DROVE}\left(\mathrm{e}_{1}\right) \wedge \operatorname{Ag}\left(\mathrm{e}_{1}\right)=\mathrm{JOHN} \wedge \mathrm{Th}\left(\mathrm{e}_{1}\right)=\mathrm{THE} C A R\right. \\
& \left.\wedge \operatorname{DRUNK}\left(\mathrm{e}_{2}\right) \wedge \operatorname{Arg}_{1}\left(\mathrm{e}_{2}\right)=\mathrm{JOHN} \wedge \tau\left(\mathrm{e}_{1}\right) \sqsubseteq \tau\left(\mathrm{e}_{2}\right)\right]
\end{aligned}
$$

In addition to the constraint of temporal dependency, there is a well known constraint that the secondary predicate and the matrix verb must share a thematic argument (Williams 1980, Rothstein 1983). It is this constraint which rules out intransitive depictives such as (38), with the reading "John drove while Mary was drunk".

\section{John drove Mary drunk}

Under this reading, John is the single argument of drove, while Mary is the single argument of drunk, and the two predicates do not share an argument.

I suggest that the two constraints, the constraint of temporal dependency and the constraint that $e_{1}$ and $e_{2}$ share an argument, combine to form the content of a PART-OF relation which holds between two events when the first is PART-OF the second. The PARTOF relation that I have in mind is not the standard part-of relation, defined in terms of the sum operation, which forms a partial order, (such as the temporal 'part-of relation used in (36)). Instead, PART-OF is a non-transitive relation which identifies one atomic eventuality as part of another analogous to the way in which, in the domain of individuals, John's hand is part of John, although both are singularities with respect to the plurality part-of relation. It is clear that while John's hand is part of John in a very fundamental way, the relation between these two elements is not the standard part-of relation since it is obviously non-transitive; if John's hand is part of him and John is part of the class, it does not mean that John's hand is part of the class. John's hand is part of John in the sense that they both share 'stuff'. You cannot take away a part of John's hand without taking away part of John. But despite this relation between them, John and his hand both remain atomic individuals, and and the grammar treats them as such; for example they can be conjoined in the appropriate circumstances. Imagine that John is visiting a holistic doctor who says (39) to him:

(39) I can't just treat your hand. I have to treat your hand and you.

It is this kind of non-transitive part of relation that I claim holds between the eventualities involved in secondary predication. When we assert that "John drove the car drunk" we assert that there is a sum of two events, the driving the car event and the being drunk event which do not just overlap temporally, but which are inextricable attached to each other since they share a participant which is involved in both these events at the same time.

We define the PART-OF relation as in (40):

$$
\begin{aligned}
& \text { PART-OF } \left.\left(\mathrm{e}_{1}, \mathrm{e}_{2}\right) \text { iff (i) } \tau\left(\mathrm{e}_{1}\right) \sqsubseteq \tau\left(\mathrm{e}_{2}\right) \text { (i.e. } \mathrm{e}_{1} \text { is temporally contained in } \mathrm{e}_{2}\right) \text {; } \\
& \text { and (ii) } \mathrm{e}_{1} \text { and } \mathrm{e}_{2} \text { share a participant. }
\end{aligned}
$$

It is the sharing a participant which makes the PART-OF relation for events non-transitive. If John drives the car while he is angry with Mary, then the event of John driving the car is PART-OF the event of John being angry with Mary since the first is temporally contained in 
the second and they share a participant. The event of John being angry at Mary may well be PART-OF another event such as the event of Mary being at a party without John. But we would not want to say that the event of John driving the car was PART-OF the event of Mary being at a party without him. (41) gives the secondary predication rule modified to include the PART-OF condition, where PART-OF is defined as in (40) above.

$$
s^{D}\left(\alpha\left(e_{1}\right), \beta\left(e_{2}\right)\right)=\lambda e . \exists e_{1} \exists e_{2}\left[e={ }^{s}\left(e_{1} \sqcup e_{2}\right) \wedge \alpha\left(e_{1}\right) \wedge \beta\left(e_{2}\right) \wedge \operatorname{PART}-O F\left(e_{1}, e_{2}\right)\right]
$$

's $\left(e_{1} \sqcup e_{2}\right)^{\prime}$, then, is a sum of events with the constraint that $e_{1}$ is PART-OF $e_{2}$ in the sense given in (40). The interpretation of "John drove the car drunk" is then as in (42):

\section{(42) $\exists \mathrm{e} \exists \mathrm{e}_{1} \exists \mathrm{e}_{2}\left[\mathrm{e}={ }^{\mathrm{S}}\left(\mathrm{e}_{1} \sqcup \mathrm{e}_{2}\right) \wedge \operatorname{DROVE}\left(\mathrm{e}_{1}\right) \wedge \operatorname{Ag}\left(\mathrm{e}_{1}\right)=\mathrm{JOHN} \wedge \mathrm{Th}\left(\mathrm{e}_{1}\right)=\mathrm{THE} \mathrm{CAR}\right.$ $\left.\wedge \operatorname{DRUNK}\left(\mathrm{e}_{2}\right) \wedge \operatorname{Exp}\left(\mathrm{e}_{2}\right)=\mathrm{JOHN} \wedge \operatorname{PART}-\mathrm{OF}\left(\mathrm{e}_{1}, \mathrm{e}_{2}\right)\right]$

\begin{abstract}
"There was a singular event e, formed out of the sum of $e_{1}$ and $e_{2}$, and which is located in the past, where $e_{1}$ is an event of the police arresting John and $\mathrm{e}_{2}$ is an event of John being drunk, and $\mathrm{e}_{1}$ is PART- OF $\mathrm{e}_{2} . "$
\end{abstract}

The PART-OF condition as formalised in (40) needs one crucial modification. As it stands, condition (ii) is stated in semantic terms, as a constraint on shared participants. But while this is adequate to rule out (39), the ungrammatical status of 'false reflexive' depictives, such as (43), show that it has to be stated as a grammatical condition. (43) is ungrammatical, even though the two events involved, the event of John singing and the event of John being asleep, do have a shared participant.

*John sang himself asleep. (cannot mean "John sang while he was asleep")

This means that the PART-OF condition cannot be constrained in terms of shared participants, but must be constrained in terms of a grammatical correlate, and stated as a condition on thematic arguments. It is not enough that the two events involved must share a participant, but the event predicates involved must also share a thematic argument. The grammatical reflex of (40) is given in (44):

(44) If a grammatical operation $\Delta$ affecting $\mathrm{e}_{1}$ and $\mathrm{e}_{2}$ introduces PART-OF $\left(\mathrm{e}_{1}, \mathrm{e}_{2}\right)$, then $\Delta$ must involve applying $e_{1}$ and $e_{2}$ simultaneously to a single thematic argument.

Alternatively, we define PART-OF as in (45), where I assume that the value of a thematic role is given as the denotation of a particular DP. (45) requires the $\mathrm{m}^{\text {th }} \theta$-role of $\mathrm{e}_{1}$ and the $\mathrm{n}^{\text {th }} \theta$-role of $\mathrm{e}_{2}$ to be assigned to the same DP argument:

$$
\text { If PART-OF }\left(e_{1}, e_{2}\right) \text {, then } \tau\left(e_{1}\right) \sqsubseteq \tau\left(e_{2}\right) \wedge \theta_{m}\left(e_{1}\right)=\theta_{n}\left(e_{2}\right)
$$

This guarantees that $e_{1}$ and $e_{2}$ share a thematic argument without forcing the application to a shared argument to be part of the summing operation itself. We will see below, when we look at the details of the derivations of subject-oriented depictives, that this is the better option. That the shared argument is always the external argument of the secondary predicate follows independently from locality conditions on thematic role assignment. 
Let us see exactly how the derivations work for object-oriented and subject-oriented depictives respectively. I use the ambiguous (46) to show how both readings are derived:

(46) The police arrested John drunk

The object-oriented reading of (46) involves applying the sum operation in (41) to the predicates denoted by arrest and drunk and applying them to the shared argument John, as in line 4 of the derivation below. Following Rothstein (in press), I assume a theory of predication in which VPs and APs denote sets of events (i.e. are of type $<e, t>$ ), and in which a predication operation shifts VP and AP meanings into type $\langle\mathrm{d},<\mathrm{e}, \mathrm{t}\rangle\rangle$ (where $\mathrm{d}$ is the type of individuals) by taking $\alpha \rightarrow \lambda \mathrm{x} . \alpha$. In such a theory, a lexical head which assigns $\mathrm{n}$ theta-roles will thus normally denote an expression of type $\left\langle\mathrm{d}_{\mathrm{n}-1} \ldots . . \mathrm{d}_{1},\langle\mathrm{e}, \mathrm{t}\rangle\right\rangle$, and, after applying to all its internal arguments will result in an XP expression of type $<e, t>$ of the form $\lambda e . \varphi$, where $\varphi$ contains an expression of the form $\theta(\mathrm{e})=\mathrm{x}$. Predication then maps this expression into $\lambda \times \lambda \mathrm{e} . \varphi$, where the $\lambda x$ binds the free variable contained in $\varphi$, at which point the whole expression can be applied to an external argument. (See Rothstein (in press) for details.) In this framework, the $S$ operation applies to predicates of type $\langle$ d, $<$ e,t $>>$, namely $\lambda y \lambda e . A R R E S T(e) \wedge A g(e)=x$ $\wedge \mathrm{Th}(\mathrm{e})=\mathrm{y}$ and $\lambda \mathrm{x} \lambda \mathrm{e} . \operatorname{DRUNK}(\mathrm{e}) \wedge \operatorname{Arg}(\mathrm{e})=\mathrm{x}$, as shown below.

Here is the derivation for the object-oriented reading of (46):

1. $\quad[\text { arrest }]_{\mathrm{V}} \rightarrow \lambda y \lambda \mathrm{e} . \operatorname{ARREST}(\mathrm{e}) \wedge \mathrm{Ag}(\mathrm{e})=\mathrm{x} \wedge \mathrm{Th}(\mathrm{e})=\mathrm{y}$

2. $[\text { drunk }]_{\mathrm{A}} \rightarrow \lambda \mathrm{e} . \operatorname{DRUNK}(\mathrm{e}) \wedge \operatorname{Arg}_{1}(\mathrm{e})=\mathrm{x}$

3. $[\text { drunk }]_{\mathrm{AP}} \rightarrow \lambda \times \lambda$ e.DRUNK(e) $\wedge \operatorname{Arg}_{1}(\mathrm{e})=$

(by predicate formation)

4. [arrest John drunk $]_{\mathrm{V}^{\prime}} \rightarrow$

$\mathrm{S}^{\mathrm{D}}\left(\lambda \mathrm{y} \lambda \mathrm{e} \cdot \operatorname{ARREST}(\mathrm{e}) \wedge \mathrm{Ag}(\mathrm{e})=\mathrm{x} \wedge \mathrm{Th}(\mathrm{e})=\mathrm{y}, \lambda \mathrm{x} \lambda \mathrm{e} \cdot \mathrm{DRUNK}(\mathrm{e}) \wedge \operatorname{Arg}_{1}(\mathrm{e})=\mathrm{x}\right)(\mathrm{JOHN})$

$=\lambda \mathrm{e} \cdot \exists \mathrm{e}_{1} \exists \mathrm{e}_{2}\left[\mathrm{e}={ }^{\mathrm{S}}\left(\mathrm{e}_{1} \sqcup \mathrm{e}_{2}\right) \wedge \operatorname{ARREST}\left(\mathrm{e}_{1}\right) \wedge \operatorname{Ag}\left(\mathrm{e}_{1}\right)=\mathrm{x} \wedge \mathrm{Th}\left(\mathrm{e}_{1}\right)=\mathrm{y} \wedge \operatorname{DRUNK}\left(\mathrm{e}_{2}\right)\right.$

$\left.\wedge \operatorname{Arg}_{1}\left(e_{2}\right)=y \wedge \operatorname{PART}-\mathrm{OF}\left(\mathrm{e}_{1}, \mathrm{e}_{2}\right)\right](\mathrm{JOHN}) \quad$ (by the summing operation)

$=\lambda \mathrm{e} \cdot \exists \mathrm{e}_{1} \exists \mathrm{e}_{2}\left[\mathrm{e}={ }^{\mathrm{s}}\left(\mathrm{e}_{1} \sqcup \mathrm{e}_{2}\right) \wedge \operatorname{ARREST}\left(\mathrm{e}_{1}\right) \wedge \operatorname{Ag}\left(\mathrm{e}_{1}\right)=\mathrm{x} \wedge \mathrm{Th}\left(\mathrm{e}_{1}\right)=\mathrm{JOHN}\right.$

$\wedge \operatorname{DRUNK}\left(e_{2}\right) \wedge \operatorname{Arg}_{1}\left(e_{2}\right)=J O H N \wedge$ PART $\left.-O F\left(e_{1}, e_{2}\right)\right]$

5. [arrest John drunk $]_{\mathrm{VP}} \rightarrow$

$$
\begin{aligned}
& \lambda \times \lambda e . \exists e_{1} \exists e_{2}\left[e=s\left(e_{1} \sqcup e_{2}\right) \wedge \operatorname{ARREST}\left(e_{1}\right) \wedge \operatorname{Ag}\left(e_{1}\right)=x \wedge \operatorname{Th}\left(e_{1}\right)=\operatorname{JOHN} \wedge \operatorname{DRUNK}\left(e_{2}\right)\right. \\
& \left.\wedge \operatorname{Arg}_{1}\left(e_{2}\right)=J O H N \wedge P A R T-O F\left(e_{1}, e_{2}\right)\right] \quad \text { (by predicate formation) }
\end{aligned}
$$

6. [the police arrested John drunk] $\rightarrow$

$$
\begin{aligned}
& \lambda \times \lambda e . \exists e_{1} \exists e_{2}\left[e={ }^{S}\left(e_{1} \sqcup e_{2}\right) \wedge \operatorname{ARREST}\left(e_{1}\right) \wedge \operatorname{Ag}\left(e_{1}\right)=x \wedge \operatorname{Th}\left(e_{1}\right)=J O H N \wedge \operatorname{DRUNK}\left(e_{2}\right)\right. \\
& \left.\wedge \operatorname{Arg}_{1}\left(\mathrm{e}_{2}\right)=\mathrm{JOHN} \wedge \mathrm{PART}-\mathrm{OF}\left(\mathrm{e}_{1}, \mathrm{e}_{2}\right)\right] \wedge \mathrm{PAST}(\mathrm{e})(\mathrm{THE} \mathrm{POLICE}) \\
& =\lambda \mathrm{e} \cdot \exists \mathrm{e}_{1} \exists \mathrm{e}_{2}\left[\mathrm{e}={ }^{\mathrm{S}}\left(\mathrm{e}_{1} \sqcup \mathrm{e}_{2}\right) \wedge \operatorname{ARREST}\left(\mathrm{e}_{1}\right) \wedge \operatorname{Ag}\left(\mathrm{e}_{1}\right)=\mathrm{THE} \text { POLICE } \wedge \mathrm{Th}\left(\mathrm{e}_{1}\right)=\mathrm{JOHN}\right. \\
& \left.\wedge \operatorname{DRUNK}\left(\mathrm{e}_{2}\right) \wedge \operatorname{Arg}_{1}\left(\mathrm{e}_{2}\right)=\mathrm{JOHN} \wedge \operatorname{PART}-\mathrm{OF}\left(\mathrm{e}_{1}, \mathrm{e}_{2}\right)\right] \wedge \operatorname{PAST}(\mathrm{e})
\end{aligned}
$$

7. $\exists \mathrm{e}\left[\exists \mathrm{e}_{1} \exists \mathrm{e}_{2}\left[\mathrm{e}={ }^{\mathrm{s}}\left(\mathrm{e}_{1} \sqcup \mathrm{e}_{2}\right) \wedge \operatorname{ARREST}\left(\mathrm{e}_{1}\right) \wedge \operatorname{Ag}\left(\mathrm{e}_{1}\right)=\mathrm{THE}\right.\right.$ POLICE $\wedge \mathrm{Th}\left(\mathrm{e}_{1}\right)=\mathrm{JOHN}$

$$
\left.\left.\wedge \operatorname{DRUNK}\left(e_{2}\right) \wedge \operatorname{Arg}_{1}\left(e_{2}\right)=J O H N \wedge \operatorname{PART}-\mathrm{OF}\left(e_{1}, e_{2}\right)\right] \wedge \operatorname{PAST}(e)\right]
$$

(by existential quantification)

i.e. "There was an event which was the sum of an event of the police arresting John and an event of John being drunk which took place in the past and the event of the police arresting John was PART-OF the event of John being drunk." 
The subject-oriented reading of (46) is slightly more complicated to derive, since at the point at which the summing operation is to apply, the expressions to be conjoined are of different types, as we see in line 5 below. The operation we use is a modified version of the summing operation in (41), which guarantees that the expressions will be of the right type to be conjoined. (Details of the analysis are given in Rothstein (in press), where the operation is called predicate absorption).

$$
\begin{aligned}
& \mathrm{S} *\left(\lambda \mathrm{e}_{1} \cdot \alpha\left(\mathrm{e}_{1}\right), \lambda \times \lambda \mathrm{e}_{2} \cdot \beta\left(\mathrm{e}_{2}\right)(\mathrm{x})\right)= \\
& \lambda \mathrm{e} . \exists \mathrm{e}_{1} \exists \mathrm{e}_{2}\left[\mathrm{e}={ }^{\mathrm{S}}\left(\mathrm{e}_{1} \sqcup \mathrm{e}_{2}\right) \wedge \alpha\left(\mathrm{e}_{1}\right) \wedge \beta\left(\mathrm{e}_{2}\right) \wedge \mathrm{PART}-\mathrm{OF}\left(\mathrm{e}_{1}, \mathrm{e}_{2}\right)\right]
\end{aligned}
$$

Here is the derivation for the subject-oriented reading of (46):

1. $\quad[\text { arrest }]_{\mathrm{v}} \rightarrow \lambda y \lambda \mathrm{e} \cdot \operatorname{ARREST}(\mathrm{e}) \wedge \operatorname{Ag}(\mathrm{e})=\mathrm{x} \wedge \mathrm{Th}(\mathrm{e})=\mathrm{y}$

2. $\quad$ arrest John $]_{\mathrm{V}^{\prime}} \rightarrow \lambda \mathrm{y} \lambda \mathrm{e} \cdot \operatorname{ARREST}(\mathrm{e}) \wedge \mathrm{Ag}(\mathrm{e})=\mathrm{x} \wedge \mathrm{Th}(\mathrm{e})=\mathrm{y}(\mathrm{JOHN})$

$=\lambda \mathrm{e} \cdot \operatorname{ARREST}(\mathrm{e}) \wedge \operatorname{Ag}(\mathrm{e})=\mathrm{x} \wedge \mathrm{Th}(\mathrm{e})=\mathrm{JOHN}$

3. $[\text { drunk }]_{\mathrm{A}} \rightarrow \lambda$ e.DRUNK(e) $\wedge \operatorname{Arg}_{1}(\mathrm{e})=\mathrm{x}$

4. $[\text { drunk }]_{\mathrm{AP}} \rightarrow \lambda \mathrm{x} \lambda \mathrm{e} . \operatorname{DRUNK}(\mathrm{e}) \wedge \operatorname{Arg}_{1}(\mathrm{e})=\mathrm{x}$

(by predicate formation)

5. [arrest John drunk $]_{\mathrm{VP}} \rightarrow$

$\mathrm{S}^{*}\left(\lambda \mathrm{e} \cdot \operatorname{ARREST}(\mathrm{e}) \wedge \operatorname{Ag}(\mathrm{e})=\mathrm{x} \wedge \mathrm{Th}(\mathrm{e})=\mathrm{JOHN}, \lambda \mathrm{x} \lambda \mathrm{e} \cdot \operatorname{DRUNK}(\mathrm{e}) \wedge \operatorname{Arg}_{1}(\mathrm{e})=\mathrm{x}(\mathrm{x})\right)$

$=\lambda \mathrm{e} \cdot \exists \mathrm{e}_{1} \exists \mathrm{e}_{2}\left[\mathrm{e}={ }^{\mathrm{s}}\left(\mathrm{e}_{1} \sqcup \mathrm{e}_{2}\right) \wedge \operatorname{ARREST}\left(\mathrm{e}_{1}\right) \wedge \operatorname{Ag}\left(\mathrm{e}_{1}\right)=\mathrm{x} \wedge \operatorname{Th}\left(\mathrm{e}_{1}\right)=\mathrm{JOHN}\right.$

$\left.\wedge \operatorname{DRUNK}\left(\mathrm{e}_{2}\right) \wedge \operatorname{Arg}_{1}\left(\mathrm{e}_{2}\right)=\mathrm{x} \wedge \operatorname{PART}-\mathrm{OF}\left(\mathrm{e}_{1}, \mathrm{e}_{2}\right)\right] \quad$ (by the summing* operation)

6. [arrest John drunk $]_{\mathrm{VP}} \rightarrow$

$\lambda \times \lambda \mathrm{e} . \exists \mathrm{e}_{1} \exists \mathrm{e}_{2}\left[\mathrm{e}={ }^{\mathrm{s}}\left(\mathrm{e}_{1} \sqcup \mathrm{e}_{2}\right) \wedge \operatorname{ARREST}\left(\mathrm{e}_{1}\right) \wedge \operatorname{Ag}\left(\mathrm{e}_{1}\right)=\mathrm{x} \wedge \operatorname{Th}\left(\mathrm{e}_{1}\right)=\mathrm{JOHN}\right.$

$\left.\wedge \operatorname{DRUNK}\left(\mathrm{e}_{2}\right) \wedge \operatorname{Arg}_{1}\left(\mathrm{e}_{2}\right)=\mathrm{x} \wedge \operatorname{PART}-\mathrm{OF}\left(\mathrm{e}_{1}, \mathrm{e}_{2}\right)\right] \quad$ (by predicate formation)

7. [the police arrested John drunk] $\rightarrow$

$\lambda \times \lambda e . \exists e_{1} \exists e_{2}\left[e={ }^{s}\left(e_{1} \sqcup e_{2}\right) \wedge \operatorname{ARREST}\left(e_{1}\right) \wedge \operatorname{Ag}\left(e_{1}\right)=x \wedge \operatorname{Th}\left(e_{1}\right)=J O H N\right.$

$\left.\wedge \operatorname{DRUNK}\left(\mathrm{e}_{2}\right) \wedge \operatorname{Arg}_{1}\left(\mathrm{e}_{2}\right)=\mathrm{x} \wedge \operatorname{PART}-\mathrm{OF}\left(\mathrm{e}_{1}, \mathrm{e}_{2}\right) \wedge \operatorname{PAST}(\mathrm{e})\right](\mathrm{THE}$ POLICE$)$

$=\lambda \mathrm{e} \cdot \exists \mathrm{e}_{1} \exists \mathrm{e}_{2}\left[\mathrm{e}={ }^{\mathrm{s}}\left(\mathrm{e}_{1} \sqcup \mathrm{e}_{2}\right) \wedge \operatorname{ARREST}\left(\mathrm{e}_{1}\right) \wedge \operatorname{Ag}\left(\mathrm{e}_{1}\right)=\mathrm{THE}\right.$ POLICE $\wedge \mathrm{Th}\left(\mathrm{e}_{1}\right)=\mathrm{JOHN}$

$\left.\wedge \operatorname{DRUNK}\left(\mathrm{e}_{2}\right) \wedge \operatorname{Arg}_{1}\left(\mathrm{e}_{2}\right)=\mathrm{THE} \operatorname{POLICE} \wedge \operatorname{PART}-\mathrm{OF}\left(\mathrm{e}_{1}, \mathrm{e}_{2}\right)\right] \wedge \operatorname{PAST}(\mathrm{e})$

8. $\exists e\left[\exists e_{1} \exists e_{2}\left[e={ }^{S}\left(e_{1} \sqcup e_{2}\right) \wedge \operatorname{ARREST}\left(e_{1}\right) \wedge \operatorname{Ag}\left(e_{1}\right)=T H E\right.\right.$ POLICE $\wedge \mathrm{Th}\left(e_{1}\right)=J O H N$ $\left.\left.\wedge \operatorname{DRUNK}\left(\mathrm{e}_{2}\right) \wedge \operatorname{Arg}_{1}\left(\mathrm{e}_{2}\right)=\mathrm{THE} \operatorname{POLICE} \wedge \operatorname{PART}-\mathrm{OF}\left(\mathrm{e}_{1}, \mathrm{e}_{2}\right)\right] \wedge \operatorname{PAST}(\mathrm{e})\right]$

(by existential quantification)

i.e. "There was an event which was the sum of an event of the police arresting John and an event of the police being drunk which took place in the past and the event of the police arresting John was PART-OF the event of the police being drunk."

Lines 5-7 in this derivation show that defining the condition on shared arguments as in (45) rather than as (44) is preferable. The summing operation $S^{*}$ used here requires the secondary predicate to be applied to a distinguished variable, which has the effect of guaranteeing that (45) is met, and crucially, the derivation of subject-oriented predicates shows that the summing operation and application of its output to an argument are two distinct operations, which are separated from each other in the derivation by predicate formation, which means that the condition as stated in (44) cannot be met. 


\section{The semantics of resultatives}

\subsection{The interpretation of simple resultatives}

This account given above is sufficient to get us the essential semantics of depictive predicates. The next stage is to extend the account to explain how resultatives work. I assume Dowty's (1979) analysis of aspectual classes, reformulated in an event style framework, which gives the basic structure of the aspectual classes as follows:
a. States:
$\lambda$ e.P(e)
b. Activities:
$\lambda \mathrm{e} .(\mathrm{DO}(\mathrm{P}))(\mathrm{e})$
c. Achievements:
$\lambda$ e. $(\mathrm{BECOME}(\mathrm{P}))(\mathrm{e})$
d. Accomplishments:
$\lambda e . \exists \mathrm{f}_{1} \exists \mathrm{f}_{2}\left[\mathrm{e}==^{\mathrm{s}}\left(\mathrm{f}_{1} \sqcup \mathrm{f}_{2}\right) \wedge(\mathrm{DO}(\mathrm{P}))\left(\mathrm{f}_{1}\right) \wedge\right.$
$\left.\left(\operatorname{BECOME}\left(\mathrm{P}^{\prime}\right)\right)\left(\mathrm{f}_{2}\right) \wedge \mathrm{Cul}(\mathrm{e})=\mathrm{f}_{2}\right]$

Deriving simple resultatives such as (48) is straightforward.

(48) Mary painted the house red.

We assume that the summing operation can apply to any pair of predicates. The difference between depictives and resultatives is in the location of the PART-OF condition on complex event formation via summing. With depictives, the PART-OF relation relates the event argument of the matrix verb and the event argument of the adjectival predicate. With resultatives, the PART-OF relation relates the culmination of the matrix verb, $\mathrm{e}_{1}$ and the event argument of the adjectival predicate, as summed up in (49):

$$
\begin{array}{ll}
\text { depictives: } & \lambda e \cdot \exists \mathrm{e}_{1} \exists \mathrm{e}_{2}\left[\mathrm{e}==^{\mathrm{s}}\left(\mathrm{e}_{1} \sqcup \mathrm{e}_{2}\right) \wedge \text { PART-OF }\left(\mathrm{e}_{1}, \mathrm{e}_{2}\right)\right] \\
\text { resultatives: } & \lambda \mathrm{e} \cdot \exists \mathrm{e}_{1} \exists \mathrm{e}_{2}\left[\mathrm{e}={ }^{\mathrm{s}}\left(\mathrm{e}_{1} \sqcup \mathrm{e}_{2}\right) \wedge \text { PART-OF }\left(\operatorname{cul}\left(\mathrm{e}_{1}\right), \mathrm{e}_{2}\right)\right]
\end{array}
$$

Resultative conjunction is object-oriented, and thus the process conjoins expressions at type $<\mathrm{d},<\mathrm{e}, \mathrm{t}>>$ :

(50) Resultative conjunction: $S^{R}\left(\alpha\left(e_{1}, y\right), \beta\left(e_{2}, y\right)\right)=$

$$
\lambda y \lambda \mathrm{e} . \exists \mathrm{e}_{1} \exists \mathrm{e}_{2}\left[\mathrm{e}^{-}={ }^{\mathrm{s}}\left(\mathrm{e}_{1} \sqcup \mathrm{e}_{2}\right) \wedge \alpha\left(\mathrm{e}_{1}, \mathrm{y}\right) \wedge \beta\left(\mathrm{e}_{2}, \mathrm{y}\right) \wedge \operatorname{PART}-\mathrm{OF}\left(\mathrm{cul}\left(\mathrm{e}_{1}\right), \mathrm{e}_{2}\right)\right]
$$

In the derivation of (48), resultative conjunction will conjoin the two expressions in (51):

$$
\begin{aligned}
& \alpha=\lambda y \lambda e \cdot \operatorname{PAINT}(\mathrm{e}) \wedge \operatorname{Ag}(\mathrm{e})=\mathrm{x} \wedge \mathrm{Th}(\mathrm{e})=\mathrm{y} \\
& \beta=\lambda \mathrm{x} \lambda \mathrm{e} \cdot \operatorname{RED}(\mathrm{e}) \wedge \operatorname{Arg}_{1}(\mathrm{e})=\mathrm{x}
\end{aligned}
$$

The derivation will be as follows:

1. $[\text { Paint }]_{\mathrm{V}} \rightarrow \lambda \mathrm{y} \lambda \mathrm{e} . \mathrm{PAINT}(\mathrm{e}) \wedge \mathrm{Ag}(\mathrm{e})=\mathrm{x} \wedge \mathrm{Th}(\mathrm{e})=\mathrm{y}$

2. $[\text { Red }]_{\mathrm{A}} \rightarrow \lambda \mathrm{e} \cdot \operatorname{RED}(\mathrm{e}) \wedge \operatorname{Arg}_{1}(\mathrm{e})=\mathrm{x}$

3. $[\operatorname{Red}]_{\mathrm{AP}} \rightarrow \lambda \mathrm{x} \lambda \mathrm{e} \cdot \operatorname{RED}(\mathrm{e}) \wedge \operatorname{Arg}_{1}(\mathrm{e})=\mathrm{x}$ (by predicate formation) 
4. [Paint the house red $]_{\mathrm{V}^{\prime}} \rightarrow$

$\mathrm{S}^{\mathrm{R}}\left(\lambda \mathrm{y} \lambda \mathrm{e} \cdot \mathrm{PAINT}(\mathrm{e}) \wedge \operatorname{Ag}(\mathrm{e})=\mathrm{x} \wedge \mathrm{Th}(\mathrm{e})=\mathrm{y}, \lambda \mathrm{x} \lambda \mathrm{e} \cdot \mathrm{RED}(\mathrm{e}) \wedge \operatorname{Arg}_{1}(\mathrm{e})=\mathrm{x}\right)(\mathrm{THE}$ HOUSE $)$

$=\lambda \mathrm{e} \cdot \exists \mathrm{e}_{1} \exists \mathrm{e}_{2}\left[\mathrm{e}=\mathrm{s}\left(\mathrm{e}_{1} \sqcup \mathrm{e}_{2}\right) \wedge \operatorname{PAINT}\left(\mathrm{e}_{1}\right) \wedge \operatorname{Ag}\left(\mathrm{e}_{1}\right)=\mathrm{x} \wedge\right.$ Th( $\left.\mathrm{e}_{1}\right)=\mathrm{THE}$ HOUSE $\wedge \operatorname{RED}\left(\mathrm{e}_{2}\right)$ $\wedge \operatorname{Arg}_{1}\left(e_{2}\right)=$ THE HOUSE $\wedge$ PART-OF $\left.\left(\operatorname{cul}\left(e_{1}\right), e_{2}\right)\right] \quad$ (by resultative summing)

5. [Paint the house red $]_{\mathrm{VP}} \rightarrow$

$\lambda \times \lambda e . \exists e_{1} \exists e_{2}\left[e=s\left(e_{1} \sqcup e_{2}\right) \wedge \operatorname{PAINT}\left(e_{1}\right) \wedge \operatorname{Ag}\left(e_{1}\right)=x \wedge \operatorname{Th}\left(e_{1}\right)=T H E\right.$ HOUSE $\wedge$ RED $\left(e_{2}\right)$ $\wedge \operatorname{Arg}_{1}\left(e_{2}\right)=T H E$ HOUSE $\wedge$ PART-OF $\left.\left(\operatorname{cul}\left(e_{1}\right), e_{2}\right)\right] \quad$ (by predicate formation)

6. [Mary painted the house red] $\rightarrow$

$\lambda \times \lambda e . \exists e_{1} \exists e_{2}\left[e={ }^{s}\left(e_{1} \sqcup e_{2}\right) \wedge \operatorname{PAINT}\left(e_{1}\right) \wedge \operatorname{Ag}\left(e_{1}\right)=x \wedge \operatorname{Th}\left(e_{1}\right)=\right.$ THE HOUSE $\left.\left.\wedge \operatorname{RED}\left(\mathrm{e}_{2}\right) \wedge \operatorname{Arg}_{1}\left(\mathrm{e}_{2}\right)=\mathrm{THE} H \mathrm{HOUSE} \wedge \mathrm{PART}-\mathrm{OF}\left(\operatorname{cul}\left(\mathrm{e}_{1}\right), \mathrm{e}_{2}\right)\right] \wedge \operatorname{PAST}(\mathrm{e})\right](\mathrm{MARY})$

$=\lambda e \cdot \exists e_{1} \exists e_{2}\left[e=s\left(e_{1} \sqcup e_{2}\right) \wedge \operatorname{PAINT}\left(e_{1}\right) \wedge \operatorname{Ag}\left(e_{1}\right)=\right.$ MARY $\wedge$ Th $\left(e_{1}\right)=T H E$ HOUSE $\wedge \operatorname{RED}\left(\mathrm{e}_{2}\right) \wedge \operatorname{Arg}_{1}\left(\mathrm{e}_{2}\right)=\mathrm{THE}$ HOUSE $\left.\wedge \operatorname{PART}-\mathrm{OF}\left(\operatorname{cul}\left(\mathrm{e}_{1}\right), \mathrm{e}_{2}\right)\right] \wedge \operatorname{PAST}(\mathrm{e})$

7. $\exists \mathrm{e}\left[\exists \mathrm{e}_{1} \exists \mathrm{e}_{2}\left[\mathrm{e}={ }^{\mathrm{S}}\left(\mathrm{e}_{1} \sqcup \mathrm{e}_{2}\right) \wedge \operatorname{PAINT}\left(\mathrm{e}_{1}\right) \wedge \operatorname{Ag}\left(\mathrm{e}_{1}\right)=\mathrm{MARY} \wedge \mathrm{Th}\left(\mathrm{e}_{1}\right)=\mathrm{THE}\right.\right.$ HOUSE $\wedge \operatorname{RED}\left(\mathrm{e}_{2}\right) \wedge \operatorname{Arg}_{1}\left(\mathrm{e}_{2}\right)=\mathrm{THE}$ HOUSE $\left.\left.\wedge \operatorname{PART}-\mathrm{OF}\left(\operatorname{cul}\left(\mathrm{e}_{1}\right), \mathrm{e}_{2}\right)\right] \wedge \operatorname{PAST}(\mathrm{e})\right]$

(by existential quantification)

"There was an event which was the sum of an event of Mary painting the house and an event of the house being red, and the culmination point of the event of Mary painting the house was PART-OF the event of the house being red."

In other words, there was an event which was the sum of an event of Mary painting the house and an event of the house being red, and the house was red at the culmination of the painting event. This is equivalent to the paraphrases usually associated with resultative predication.

Note that we can make the structure of the resultative more explicit by applying resultative conjunction to the decomposed accomplishment. If we analyse paint as in line $1^{\prime}$. below, we will get $4^{\prime}$ and 7 ' instead of 4 and 7 in the derivation above:

$$
\begin{aligned}
& \text { 1'. } \quad \text { paint }]_{\vee} \rightarrow \lambda y \lambda e . \exists f_{1} \exists f_{2}\left[e={ }^{s}\left(f_{1} \sqcup f_{2}\right) \wedge \lambda f_{1} .(P A I N T)\left(f_{1}\right) \wedge \operatorname{Ag}\left(f_{1}\right)=x \wedge \operatorname{Th}\left(f_{1}\right)=y\right. \\
& \left.\wedge(\text { BECOME-PAINTED }))\left(\mathrm{f}_{2}\right) \wedge \mathrm{Th}\left(\mathrm{f}_{2}\right)=\mathrm{y} \wedge \mathrm{Cul}(\mathrm{e})=\mathrm{f}_{2}\right] \\
& \text { 4'. } \quad \mathrm{S}^{\mathrm{R}}\left(\lambda \mathrm { y } \lambda \mathrm { e } \cdot \exists \mathrm { f } _ { 1 } \exists \mathrm { f } _ { 2 } \left[\mathrm{e}={ }^{\mathrm{S}}\left(\mathrm{f}_{1} \sqcup \mathrm{f}_{2}\right) \wedge \lambda \mathrm{f}_{1} .(\mathrm{PAINT})\left(\mathrm{f}_{1}\right) \wedge \operatorname{Ag}\left(\mathrm{f}_{1}\right)=\mathrm{x} \wedge \operatorname{Th}\left(\mathrm{f}_{1}\right)=\mathrm{y}\right.\right. \\
& \left.\wedge(\text { BECOME-PAINTED }))\left(f_{2}\right) \wedge \operatorname{Th}\left(f_{2}\right)=y \wedge \operatorname{Cul}(e)=f_{2}\right] \text {, } \\
& \left.\lambda \times \lambda \mathrm{e} . \mathrm{RED}(\mathrm{e}) \wedge \operatorname{Arg}_{1}(\mathrm{e})=\mathrm{x}\right)(\mathrm{THE} \text { HOUSE) } \\
& \text { 7'. } \exists e\left[\exists e _ { 1 } \exists e _ { 2 } \left[e={ }^{s}\left(e_{1} \sqcup e_{2}\right) \wedge e_{1}={ }^{s}\left(f_{1} \sqcup f_{2}\right) \wedge \lambda f_{1} \cdot(\operatorname{PAINT})\left(f_{1}\right) \wedge \operatorname{Ag}\left(f_{1}\right)=M A R Y\right.\right. \\
& \left.\wedge \mathrm{Th}\left(\mathrm{f}_{1}\right)=\text { THE HOUSE } \wedge(\text { BECOME-PAINTED })\right)\left(\mathrm{f}_{2}\right) \wedge \mathrm{Th}\left(\mathrm{f}_{2}\right)=\text { THE HOUSE } \\
& \left.\left.\left.\wedge \operatorname{Cul}\left(e_{1}\right)=f_{2}\right] \wedge \operatorname{RED}\left(e_{2}\right) \wedge \operatorname{Arg}_{1}\left(e_{2}\right)=T H E \text { HOUSE } \wedge \operatorname{PART}-O F\left(\operatorname{cul}\left(e_{1}\right), e_{2}\right)\right] \wedge \operatorname{PAST}(e)\right]
\end{aligned}
$$

\subsection{Some answers to some questions}

We are now in a position to answer questions 3 and 4 asked above. First, the two kinds of secondary predicates available are depictive and resultative because of the range of distinct events which aspectual structure makes reference to and thus makes available as the first argument of the PART-OF relation. Dowty's verb classification in (47) makes reference to a 
matrix verb e, in all four verb classes, and a subevent of e, namely cul(e), in definition of accomplishments. The two available PART-OF relations are therefore PART-OF $\left(\mathrm{e}_{1}, \mathrm{e}_{2}\right)$ and PART-OF $\left(\operatorname{cul}\left(\mathrm{e}_{1}\right), \mathrm{e}_{2}\right)$. The first gives the depictive reading, since the matrix verb is PART-OF the event introduced by the adjectival predicate, giving the effect of an assertion that the matrix event is carrying on while the event introduced by the secondary predicate is going on. This leads to the common paraphrase of "John drove the car drunk" as "John drove the car when/while he was drunk". The second gives the resultative reading, since the culminative point of the matrix event is asserted to be carrying on while the event introduced by the secondary predicate is occurring. "Mary painted the house red" could then be paraphrased as "Mary painted the house and the culminating point of this event was when/while the house was red". There are no inceptives, for example, because aspectual structure relevant for linguistic classification makes no reference to the beginnings of events, and therefore these event beginnings cannot be arguments of the PART-OF relation.

It is not strictly true that only the matrix verb e or the cul(e) are the only possible first arguments of PART-OF. The structure for accomplishments makes it possible that the DO(e) subpart of an accomplishment should also be a possible first argument for PART-OF. However, if cul(e) in (47d) is instantaneous, then DO(e) is not a proper temporal part of the accomplishment. Using the whole accomplishment or its activity subpart DO(e) as the first argument of the PART-OF relation will then be equivalent.

The second question that we are now in a position to answer is why resultative predicates are apparently object-oriented. It has been clear for some time (see, e.g. Tenny 1987, and much work since then) that this is because the resultative is predicated of the incremental theme, and incremental themes appear in direct object position, but we now can give a precise statement of what this follows from. The resultative occurs when the first argument of the PART-OF relation is cul $\left(\mathrm{e}_{1}\right)$, i.e. the culmination of the matrix verb $\mathrm{e}_{1}$. We assume, following Dowty $(1979,1991)$, Tenny $(1987,1994)$, Krifka $(1992,1998)$ and others, that the culmination point of $e_{1}$ is essentially an achievement event in which a change of state occurs to the theme of $e_{1}$. This is given by the representation in (47d), and also by Dowty's formalisation of the structure of accomplishments in Dowty (1979). Crucially, in both representations, $\operatorname{cul}\left(\mathrm{e}_{1}\right)$ has a single argument, the entity to which the change of state happens. When cul $\left(e_{1}\right)$ occurs is determined intuitively by the point at which the incremental theme is 'used up'; more precisely, following the direction taken in Krifka (1998), proper parts of an accomplishment $\mathrm{e}_{1}$ with the same initial point arranged in increasing size have proper parts of the incremental theme as arguments. The culmination point of $e_{1}$ is reached at the first point at which the entire object denoted by the incremental theme is the argument of $e_{1}$. The culmination of Mary painted the house is thus the moment at which the house becomes painted, the culmination of John read the book is the point at which the whole book becomes the object of $\underline{\text { read, }}$, etc. It is a condition on the PART-OF relation that the two events involved in the relation share an argument. In this case the relevant PART-OF relation is PART$\mathrm{OF}\left(\operatorname{cul}\left(\mathrm{e}_{1}\right), \mathrm{e}_{2}\right)$, and since the single argument of $\operatorname{cul}\left(\mathrm{e}_{1}\right)$ is the incremental theme of $\mathrm{e}_{1}$, it will be by necessity the argument of $\mathrm{e}_{2}$ also. It thus follows from the condition PART$\mathrm{OF}\left(\mathrm{cul}\left(\mathrm{e}_{1}, \mathrm{e}_{2}\right)\right)$ that the resultative will have to be predicated of the incremental theme of the matrix event. And if the incremental theme is realised in the direct object position, then resultative predicate will be predicated of the direct object also. Hence the apparent direct object restriction on resultative predicates.

The correct formalisation of the 'direct object restriction' is thus that resultatives must be predicated of incremental themes. Crucially, it does not need to be stated independently, but will follow from the constraints on the PART-OF condition. Formulated like this, we can see that there is a clear prediction that if there are incremental themes which occur in subject position, then it should be possible to predicate resultatives of the surface subject, and this is what we see in (52): 
(52) a. The river froze solid.

b. The soup cooled to a jelly.

c. ${ }^{*}$ John laughed sick.

We can see that the subject is an incremental theme in $(52 \mathrm{a} / \mathrm{b})$ but not $(52 \mathrm{c})$ since in the first two cases, but not the third, the imperfective paradox occurs:

(53) a. The river was freezing (solid), but it hadn't frozen yet.

b. The soup was cooling (to a jelly), but it hadn't cooled yet.

c. \#John was laughing, but he hadn't laughed yet.

This shows, of course, that it is not possible to use the resultative construction as an argument for syntactic unaccusativity in English; we don't need to posit movement to explain subjectoriented resultatives in these cases. Raising to subject is of course compatible with the analysis presented here, and there may still be other reasons to want to continue to assume such an analysis.

\subsection{Non-thematic resultatives and fake reflexives}

As it stands, our theory has not yet answered question 5 above; in other words, it does not explain what makes possible non-thematic resultatives and the so-called 'fake reflexive examples exemplified in $(54 \mathrm{a} / \mathrm{b})$ and $(54 \mathrm{c} / \mathrm{d})$ respectively:

(54) a. John sang the baby asleep.

b. The audience laughed the clown off the stage.

c. He laughed himself sick.

d. The baby cried himself asleep.

Superficially, our theory should find these problematic, since the condition on adding a secondary predicate is that the event denoted by the secondary predicate shares an argument with the matrix verb, and this is exactly the condition which seems not to be met. In other words, the condition on the PART-OF relation, which rules out a depictive reading of "John drove Mary drunk" (discussed in (39)) should also rule these out.

Intuitively, it is more or less clear what is going on. As discussed in Dowty (1979), Tenny (1987,1994,) Levin and Rappaport Hovav (1995), the resultative is added to an activity verb and the effect is to get an accomplishment reading of the achievement. The resultative is in some sense adding a terminal point or culmination to the activity given by the main verb, and thus allowing the $\mathrm{V}+\mathrm{AP}$ to be understood as an complex verb of the accomplishment class. The question is how exactly does this work? More specifically, the question is how to find a way to 'add' a culmination point to the activity verbs in (54). On the assumption that there is a single resultative rule which applies both to transitive examples like (48) and the examples in (54), we cannot analyse the resultative as itself adding a culmination. This is because it follows from the nature of telicity and the properties of culminations that each event can have only one culmination point. Since resultative predication adds a resultative predicate to sentences where the matrix verb is a lexical accomplishment, for which the culmination is lexically defined within the meaning of the verb, resultatives cannot in general introduce culmination points. In (48), the accomplishment VP paint the house defines when its culmination occurs, namely when the house is or becomes painted, and the resultative adds a property of the culmination, namely that it is part of the event of the house being red. On the assumption that there is only one resultative rule, then even in (54) the resultative will only be 
able to give a property of the culmination and not add the culmination itself. A second point is that, as is well known, accomplishments can have a non-telic reading if their direct object is a bare plural or a mass noun. We note that non-thematic resultatives can be atelic if the subject of the resultative is a bare plural or a mass noun. $(54 \mathrm{a} / \mathrm{c})$ have atelic counterparts in (55):

a. John sang babies asleep for hours last night.

b. The audience was very cruel and laughed performers of the stage as fast as they could come on.

Since the matrix events here do not have a single culmination point, it is implausible to analyse the resultative predicate as introducing such a culmination.

The simplest assumption is that the same rule which interpreted (48) is used here, and that the resultative rule forces the aspectual class of the matrix verb to shift in order to allow the resultative to be interpreted. This will have the effect of allowing the PART-OF condition to be satisfied. It will work in the following way. What the PART-OF condition in the resultative predication operation does is look for the culmination point of the matrix predicate. If the matrix predicate is an activity which does not have a culmination point, the resultative rule provokes a SHIFT operation on the matrix verb. (I will argue below why this applies only to activity matrix predicates and not states or achievements.) Shifting SING from its natural activity reading means fitting it into an accomplishment template as below:

$$
\begin{aligned}
& \operatorname{SHIFT}(\lambda \mathrm{e} .(\mathrm{DO}(\mathrm{SING}))(\mathrm{e}) \wedge \mathrm{Ag}(\mathrm{e})=\mathrm{x})= \\
& \lambda \mathrm{y} \lambda \mathrm{e} . \exists \mathrm{f}_{1} \exists \mathrm{f}_{2}\left[\mathrm{e}={ }^{\mathrm{S}}\left(\mathrm{f}_{1} \sqcup \mathrm{f}_{2}\right) \wedge(\mathrm{DO}(\mathrm{SING}))\left(\mathrm{f}_{1}\right) \wedge \mathrm{Ag}\left(\mathrm{f}_{1}\right)=\mathrm{x} \wedge \operatorname{Th}\left(\mathrm{f}_{1}\right)=\mathrm{y} \wedge\right. \\
& \left.(\mathrm{BECOME}(\mathrm{SUNG}))\left(\mathrm{f}_{2}\right) \wedge \operatorname{Th}\left(\mathrm{f}_{2}\right)=\mathrm{y} \wedge \operatorname{cul}(\mathrm{e})=\mathrm{f}_{2}\right]
\end{aligned}
$$

Or more simply:

$$
\operatorname{SHIFT}(\lambda \mathrm{e} .(\mathrm{DO}(\mathrm{SING}))(\mathrm{e}) \wedge \operatorname{Ag}(\mathrm{e})=\mathrm{x})=\lambda \mathrm{y} \lambda \mathrm{e} \cdot \mathrm{SING}(\mathrm{e}) \wedge \mathrm{Ag}(\mathrm{e})=\mathrm{x} \wedge \mathrm{Th}(\mathrm{e})=\mathrm{y}
$$

Of course, out of context, the forms in $(56 / 57)$ do not contain enough information for them to be usable. They don't add the lexical information about what the role of the incremental theme in the singing event could be, nor what it means for the theme to 'become sung' (unless the theme is a song, of course). But, in the context of the resultative predicate, the constraints on resultative predication force information to be filled in in a particular way, and thus the derived accomplishment in (56) becomes usable. Let us see how this works with (54a).

It has been argued (Rothstein 1992, in press), Levin and Rappaport Hovav (1995), that non-thematic resultatives have a small clause structure. This means that (54a) has the syntactic structure in (58):

a. John sang the baby asleep.

(58) John sang [the baby asleep]

Resultative conjunction applies at type $<\mathrm{e}, \mathrm{t}>$ and will conjoin the following two expressions:

$\lambda$ e.SANG $(\mathrm{e}) \wedge \mathrm{Ag}(\mathrm{e})=\mathrm{x}$

$\lambda$ e.ASLEEP(e) $\wedge \operatorname{Arg}_{1}(\mathrm{e})=\mathrm{THE}$ BABY 
Applying the resultative conjunction at type $<\mathrm{e}, \mathrm{t}>$ we get:

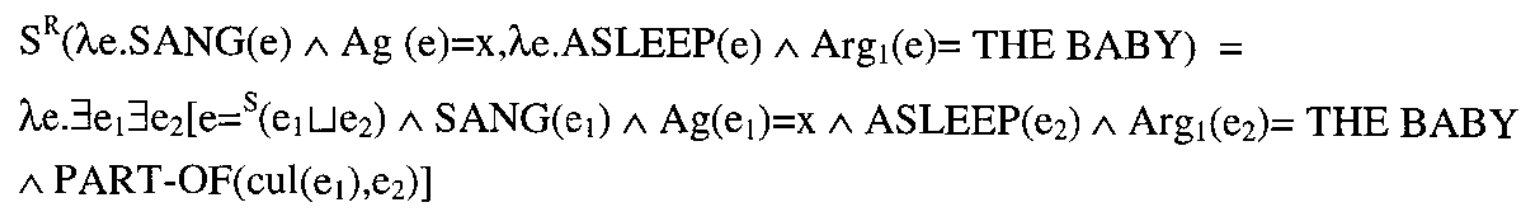

In order for this expression to be interpretable, resultative predication will force a shift in the aspectual class of sing, using the SHIFT operation in (56), and we will get a representation as follows:

$$
\begin{aligned}
& \lambda \mathrm{e} . \exists \mathrm{e}_{1} \exists \mathrm{e}_{2}\left[\mathrm{e}={ }^{\mathrm{s}}\left(\mathrm{e}_{1} \sqcup \mathrm{e}_{2}\right) \wedge \mathrm{SANG}\left(\mathrm{e}_{1}\right) \wedge \operatorname{Ag}\left(\mathrm{e}_{1}\right)=\mathrm{x} \wedge \mathrm{Th}\left(\mathrm{e}_{1}\right)=\mathrm{THE} \mathrm{BABY}\right. \\
& \left.\wedge \operatorname{ASLEEP}\left(\mathrm{e}_{2}\right) \wedge \operatorname{Arg}\left(\mathrm{e}_{2}\right)=\mathrm{THE} \text { BABY } \wedge \operatorname{PART}-\mathrm{OF}\left(\operatorname{cul}\left(\mathrm{e}_{1}\right), \mathrm{e}_{2}\right)\right]
\end{aligned}
$$

The constraints on the PART-OF relation will guarantee that there is only one way to fill in the information in the output of the SHIFT relation. There is a condition that $\operatorname{cul}\left(\mathrm{e}_{1}\right)$ is PART$\mathrm{OF} \mathrm{e}_{2}$. This means that cul $\left(\mathrm{e}_{1}\right)$ and $\mathrm{e}_{2}$ must share an argument. The argument of $\mathrm{e}_{2}$ is the baby, which must thus also be the argument of $\operatorname{cul}\left(\mathrm{e}_{1}\right)$. And since the argument of cul( $\left.\mathrm{e}_{1}\right)$ is always the incremental theme of $e_{1}$, we can supply a value for the newly introduce theme of sing*. If we use the decomposed form of sing* we will get the following more complex, but more explicit, representation:

$$
\begin{aligned}
& \lambda \text { e. } \exists e_{1} \exists e_{2}\left[\exists f _ { 1 } \exists f _ { 2 } \left[e={ }^{s}\left(e_{1} \sqcup e_{2}\right) \wedge e_{1}=s^{s}\left(f_{1} \sqcup f_{2}\right) \wedge(D O(S I N G))\left(f_{1}\right) \wedge \operatorname{Ag}\left(f_{1}\right)=x\right.\right. \\
& \left.\wedge \mathrm{Th}\left(\mathrm{f}_{1}\right)=\mathrm{THE} B A B Y \wedge(\mathrm{BECOME}(\mathrm{SUNG}))\left(\mathrm{f}_{2}\right) \wedge \mathrm{Th}\left(\mathrm{f}_{2}\right)=\mathrm{THE} B A B Y \wedge \operatorname{cul}\left(\mathrm{e}_{1}\right)=\mathrm{f}_{2}\right] \\
& \left.\wedge \operatorname{ASLEEP}\left(\mathrm{e}_{2}\right) \wedge \operatorname{Arg}_{1}\left(\mathrm{e}_{2}\right)=\mathrm{THE} \mathrm{BABY} \wedge \operatorname{PART}-\mathrm{OF}\left(\operatorname{cul}\left(\mathrm{e}_{1}\right), \mathrm{e}_{2}\right)\right]
\end{aligned}
$$

Abstraction over the $\mathrm{x}$ variable, application to the subject argument and existential closure will give us:

$$
\begin{aligned}
& \exists e\left[\exists e _ { 1 } \exists e _ { 2 } \left[\exists f _ { 1 } \exists f _ { 2 } \left[e={ }^{s}\left(e_{1} \sqcup e_{2}\right) \wedge e_{1}={ }^{s}\left(f_{1} \sqcup f_{2}\right) \wedge(D O(\operatorname{SING}))\left(f_{1}\right) \wedge \operatorname{Ag}\left(f_{1}\right)=J O H N\right.\right.\right. \\
& \left.\wedge \mathrm{Th}\left(\mathrm{f}_{1}\right)=\mathrm{THE} \text { BABY } \wedge(\text { BECOME}(\mathrm{SUNG}))\left(\mathrm{f}_{2}\right) \wedge \mathrm{Th}\left(\mathrm{f}_{2}\right)=\mathrm{THE} \text { BABY } \wedge \operatorname{cul}\left(\mathrm{e}_{1}\right)=\mathrm{f}_{2}\right] \\
& \left.\left.\wedge \operatorname{ASLEEP}\left(\mathrm{e}_{2}\right) \wedge \operatorname{Arg}_{1}\left(\mathrm{e}_{2}\right)=\mathrm{THE} \mathrm{BABY} \wedge \operatorname{PART}-\mathrm{OF}\left(\operatorname{cul}\left(\mathrm{e}_{1}\right), \mathrm{e}_{2}\right)\right]\right]
\end{aligned}
$$

"There was an event which was the sum of a singing event and an event of the baby being asleep, and the agent of the singing event was John, and the culmination of the singing event was part of the baby being asleep."

So, resultative predication (i) forces us to assign a culmination point to the event of singing and (ii), since the culmination of $e_{1}$ and the event of the baby being asleep must share an argument (by the constraint on the PART-OF condition) it forces us to assume that the baby is the argument of the culmination of $\mathrm{e}_{1}$. This means that, since culminations are defined in terms of what happens to the incremental theme of an event, the baby must be interpreted as denoting the incremental theme of the singing event.

What we see is that while, out of context the result of SHIFT(SING) in (57), is uninterpretable, in the context of a resultative we can interpret it. The accomplishment template requires the verb to assign a theme role, where the $\mathrm{V}$ appears to be intransitive, and it requires a culmination to be determined in terms of 'what happens' to the theme, without there being 
any lexical information about how the culmination is to be calculated. In the normal case, the meaning of the accomplishment includes information about what happens to the theme, and about what constitutes the culmination and how it is defined in terms of the theme. All this information is missing in the shifted form of SING. However, when there is a resultative predicate, we can calculate how to fill in the missing information which will make the result of SHIFT(SING) interpretable. The PART-OF condition requires the subject of the resultative to be interpreted as the incremental theme of SHIFT(SING), and the culmination will then be defined in terms of measuring the progress of the singing event in terms of what happens to the baby. Since the resultative tells us that a property of the culmination is that the baby is asleep at cul $\left(\mathrm{e}_{1}\right)$, it is appropriate to use as the scale of measuring the singing event the baby's progress along the path to sleep. This is the reading we got for (54a), given above. Thus we see that the same resultative rule can be used for non-thematic resultatives, as is used for ordinary transitive resultatives. Note that the examples in (55) are independent evidence that the apparently non-theta-marked DP is in fact the incremental theme of the matrix verb. They show that it is the apparently non-thematic DP which determines whether the VP is telic or atelic. When this DP is a singular count nominal, (or a nominal modified by a numerical) the VP is telic, and when it is plural (but without a numerical modifier), the VP is atelic. As Krifka (1998), as well as others, have shown, it must be the incremental theme which determines the telic/atelic status of the VP; thus (55) provides evidence that the subject of the resultative is indeed the incremental theme of the matrix verb.

The use of the reflexive pronoun in $(54 \mathrm{c} / \mathrm{d})$ follows naturally from this analysis together with standard assumptions about the theta-criterion and the use of reflexives. In simple sentences like (59), the reflexive is used to indicate that the value of the second thematic role is identical to the value of the first. Paint assigns both agent and a theme, and although the values of the two roles are identified, they must nonetheless be syntactically realised by two separate nominal expressions (DPs).

John painted himself with woad.

The same is true in $(54 \mathrm{c} / \mathrm{d})$, repeated here:

c. He laughed himself sick.

d. The baby cried himself asleep.

The subject of the resultative must be the incremental theme of the matrix verb. The basic form of the matrix verb assigns only one argument, an agent, to its external position. When it shifts, via (57) to an accomplishment form, it assigns an extra argument, and this argument is distinct from the agent. This means that the external subject cannot be both agent and theme, and consequently, another lexical DP must be added which can be both the argument of the resultative and the theme of the matrix verb.

On the assumption that the apparently non-thematic DP is in fact the incremental theme argument of the verb, we should perhaps revise our original assumption that non-thematic resultatives have a small clause complement (despite the arguments in favour of such a structure: see Rothstein (1992, in press), Levin and Rappaport Hovav (1995)). If the subject of the resultative is a theta-marked argument of the matrix verb, it should be a sister of the verb. If this is the case, then we should give the derivation of non-thematic resultatives slightly differently from above. We would have to assume that the SHIFT operation occurs to the intransitive before resultative conjunction applies. This means that resultative conjunction applies at the $\langle\mathrm{d},<\mathrm{e}, \mathrm{t}\rangle\rangle \mathrm{level}$. It conjoins the following two predicates and applies them jointly to their shared argument the baby: 
$\lambda \times \lambda e$. ASLEEP(e) $\wedge \operatorname{Arg}_{1}(\mathrm{e})=\mathrm{x}$

$$
\begin{gathered}
\lambda y \lambda e . \exists f_{1} \exists f_{2}\left[e={ }^{s}\left(f_{1} \sqcup f_{2}\right) \wedge(D O(\operatorname{SING}))\left(f_{1}\right) \wedge \operatorname{Ag}\left(f_{1}\right)=x \wedge \operatorname{Th}\left(f_{1}\right)=y\right. \\
\left.\wedge(B E C O M E(\operatorname{SUNG}))\left(f_{2}\right) \wedge \operatorname{Th}\left(f_{2}\right)=y \wedge \operatorname{cul}(e)=f_{2}\right]
\end{gathered}
$$

This gives the following expression:

$$
\begin{aligned}
& \lambda y \lambda e . \exists e_{1} \exists e_{2}\left[\exists f _ { 1 } \exists f _ { 2 } \left[e={ }^{s}\left(e_{1} \sqcup e_{2}\right) \wedge e_{1}={ }^{s}\left(f_{1} \sqcup f_{2}\right) \wedge(D O(\operatorname{SING}))\left(f_{1}\right) \wedge \operatorname{Ag}\left(f_{1}\right)=x \wedge \operatorname{Th}\left(f_{1}\right)=y\right.\right. \\
& \left.\wedge(\operatorname{BECOME}(\operatorname{SUNG}))\left(\mathrm{f}_{2}\right) \wedge \operatorname{Th}\left(\mathrm{f}_{2}\right)=y \wedge \operatorname{cul}\left(\mathrm{e}_{1}\right)=\mathrm{f}_{2}\right] \wedge \operatorname{ASLEEP}\left(\mathrm{e}_{2}\right) \wedge \operatorname{Arg}_{1}\left(\mathrm{e}_{2}\right)=\mathrm{y} \\
& \left.\wedge \text { PART-OF }\left(\operatorname{cul}\left(\mathrm{e}_{1}\right), \mathrm{e}_{2}\right)\right](\mathrm{THE} \mathrm{BABY})
\end{aligned}
$$

The same representation will result whichever way the derivation is done, and I will not adjudicate between the two possibilities here.

\section{Secondary predicates and aspectual structure}

In this section, I will compare depictive and resultative predicates with respect to their effect on aspectual structure. I call secondary predicates aspectual modifiers relying on the sense in which 'aspect' refers to the perspective from which the event is presented. Secondary predicates are aspectual elements in the sense that they do not directly give a property of the event denoted by the matrix verb in the way that adverbial modifiers do, but they allow this event to be presented in the context of its relation to another eventuality, via, crucially, the PART-OF relation. This makes the assertion, not just that the matrix event is temporally part of the eventuality introduced by the secondary predicate, but they are closely connected via a shared participant, and that there is a corresponding grammatical constraint that they share a syntactic argument. Depictive and resultative predicates work in essentially the same way, in this respect, except that depictives relate the eventuality introduced by the matrix verb to the eventuality of the secondary predicate, while resultatives relate the culmination of the matrix event to the eventuality of the secondary predicate.

This has the effect of making resultative predication more restrictive in a number of ways. We have already seen that it produces a 'direct-object' restriction, or more properly an 'incremental theme restriction' since the resultative must share an argument with the culmination event of the matrix verb, and culminations are events which occur to incremental theme arguments. We have also seen that resultative predication can force an aspectual shift in an activity verb producing an accomplishment. What about the other classes? Depictive predicates may occur with matrix verbs from all four aspectual classes, without affecting the aspectual class of the verb:

(60) a. $\mathrm{John}_{\mathrm{i}}$ was happy drunk $\mathrm{i}_{\mathrm{i}}$ (stative)

b. John ran $_{\mathrm{i}}$ drunk $_{\mathrm{i}}$. (activity)

c. $\mathrm{John}_{\mathrm{i}}$ painted the picture drunk $\mathrm{k}_{\mathrm{i}}$ (accomplishment)

d. John $n_{\mathrm{i}}$ reached the top of the mountain drunk $\mathrm{i}_{\mathrm{i}}$ (achievement)

With resultatives this is not the case. They occur with accomplishments and activities, and in the latter case they cause a shift in the aspectual class of the matrix verb. But as (61) shows, they do not occur with stative or achievements; the examples in $(61 \mathrm{a} / \mathrm{d})$ are not ungrammatical, they just have a depictive reading. 
(61) a. John loved Mary crazy $_{i}$ (stative: no resultative reading).

b. John ran the soles of his shoes thin $_{i}$ (activity $\rightarrow$ accomplishment)

c. John painted the house red $_{i}$ (accomplishment)

d. John noticed Mary upset $_{i}$ (achievement: no resultative reading)

The explanation follows from the analysis we have given. Statives have no culminations, and thus cannot take a resultative. In principle we might expect that they too can undergo a 'shift' in aspectual class into accomplishments, and in the right context, I suppose that it is possible to 'push' a reading in which (61a) means "John loved Mary and as a result she was crazy". However, there is an obvious reason why the shift operation can occur easily with activities but not states. Activities consist of a predicate which can be decomposed into $\mathrm{DO}(\alpha)$, and a component of this kind is a part of an accomplishment predicate. In other words, shifting an activity into an accomplishment does not require changing the nature of the activity involved, it requires only the addition of a method of measuring the progress of the activity in relation to a participant. States are not activities, and furthermore, they are naturally homogenous; if a state holds as an interval $i$, it holds at all instants of $i$; the effect of this is to make them static. Shifting a state into an activity doesn't just require adding a measure function, but requires changing the nature of the eventuality denoted by the original predicate, and this is much harder to do.

With achievements, we have the converse problem and the same result. Achievements are eventualities which consist solely of a culmination. Since the culmination is the whole eventuality denoted by the matrix verb and not a proper part of it, the effect of resultative predication will be identical to depictive predication.

\section{Subject-oriented resultatives}

There have been a number of works recently which have argued that the direct object restriction, whether it is phrased in terms of direct objects or incremental themes, is not correct, and that there exists a class of subject-oriented resultatives which are not predicated of incremental themes. Most prominent among these are Wechsler (1997), who offers (62a-c) as evidence, Verspoor (1997) who offers examples (62d/e) and Rappaport Hovav and Levin (1999).

(62) a. The wise men followed the star out of Bethlehem.

b. The sailors caught a breeze and rode it clear of the rocks.

c. He followed Lassie free of his captors.

d. The children played leapfrog across the park.

e. John walked the dog to the store.

f. John danced mazurkas across the room.

Hoekstra (1988) and Levin and Rappaport Hovav (1995) argue also that verbs of manner of motion and verbs of sound emission occur both in intransitive, object-oriented resultatives and as apparent subject-oriented intransitives (these examples are taken from Rappaport Hovav and Levin (1999)):

(63) a. Dan ran/hopped/jogged/danced to the station.

b. She started to run the hangover out of her system.

c. The elevator creaked to the ground floor.

d. The alarm clock buzzed them awake. 
They point out that sometimes minimal pairs are possible, although not always:

(64) a. One of the race cars wiggled loose inside the transporter.

b. The snake wiggled itself loose...

c. She danced across the room.

d. She danced herself across the room.

e. She wiggled herself comfortable in the chair.

f. * She wiggled comfortable in the chair.

Rappaport Hovav and Levin and Wechsler give competing analyses of how to explain when and why subject-oriented resultatives are possible, and I discuss their accounts in detail in Rothstein (in progress). There is no space to go into the details of the discussion here, but since it is an obvious and crucial prediction of my analysis that subject-oriented resultatives are not possible except where the subject is an incremental theme, I do want to say something about how the apparently subject-oriented examples above should be analysed.

The most pertinent observation about the apparently subject-oriented resultatives is that the XP which are supposed to be result predicates are restricted to expressions of location, and more precisely of direction. Rappaport Hovav and Levin point this out, commenting that subject-oriented resultatives are restricted to expressions which denote 'result locations' rather than states. The PPs which occur include across the room, out of Bethlehem, and to the store, and the APs too are expressions which can express a direction with respect to a fixed point such as clear of the rocks, free of his captors, and loose. Crucially, a non-directional expression such as comfortable cannot be a subject-oriented resultative. I suggest that apparently subject-oriented result predicates are not resultative predicates at all, but are internal path arguments of the verb, in the sense of Krifka (1998). A path argument can be, and usually is the incremental theme, and Krifka shows that what defines path arguments is precisely that as the matrix event grows temporally, the portion of the path which is the argument of the event grows too. Thus in an example like "John danced across the room", the verb dance is supplied with an incremental path argument across the room. The effect is analogous to a resultative predicate because the event denoted by dance across the room reaches its telic point when the path is 'used up' and that of course will be when John is across the room. This is of course the same situation as the one that occurs occurs at the telic point of "John danced himself across the room", which asserts that there is an event of dancing whose culmination point is part of the event of John being across the room.

There are various questions that are answered by this account of the examples in $(62 / 62)$ which makes it convincing. First, we explain Rappaport Hovav and Levin's observation that (so-called) subject-oriented resultatives denote result locations and not states. Since they are in fact path arguments, the telic point of the event will be when the subject is at the location designated by the end of the path - and this will be a 'result location'. Second, we explain why subject-oriented resultatives are temporally dependent; in Rappaport Hovav and Levin's words the result event unfolds at the same rate as the matrix event. If the locational expression denotes a path which is the incremental argument of the verb, and which is 'used up' gradually as the event unfolds, then of course progress along the path will be temporally dependent on the progress of the matrix event. Third, although there are minimal pairs such as $(65 \mathrm{a} / \mathrm{b})$ we see that when the PP is directional but non-telic, the object-oriented version is not as good, as in $(65 \mathrm{c} / \mathrm{d})$ :

(65) a. John danced out of the room.

b. John danced himself out of the room. 
c. John danced round and round the room.

d. ??John danced himself round and round the room.

This is because the non-telic directional phrases do not easily denote result states.

Clearly, there is a lot more to say about this topic, and the formal details of the analysis of so-called subejct-oriented resultatives still have to be worked out. There is no space for this here, but I hope I have shown the direction in which I think an analysis of these putative counterexamples should go.

\section{The next set of questions}

The analysis presented here raises a number of larger questions I want to mention, and which I hope to discuss in future work. These centre round the nature of the incremental theme role, and the question of how incrementality is to be calculated. The first is raised by examples like (66), pointed out to me by David Dowty (p.c.):

(66) John drank himself/ his friends under the table.

Here the 'non-thematic' resultative is based, not on an intransitive verb, but on a transitive accomplishment verb drink, which normally assigns the incremental theme role to the entity which is consumed, as in "John drank three glasses of beer". The standard analysis of intransitivised drink (see e.g. Dowty 1982) is that the internal thematic argument (which I will call Patient) has been bound by an existential quantifier via a lexical rule, giving a lexical form like (67):

\section{$\lambda \mathrm{e} . \exists y[D R I N K(e) \wedge \operatorname{Ag}(e)=x \wedge \operatorname{Pat}(e)=y]$}

The patient argument is usually the incremental theme, but the fact that this form can be used in (66) indicates that existential quantification over this argument has changed its status and it is no longer the incremental argument of the verb. This allows intransitivised drink to be used in (66). In Rothstein (in progress) I discuss how this occurs, and what it means for how we should understand the incremental theme role.

The second obvious question is how exactly we add an incremental theme to an intransitive verb. In other words, what available measures are there for calculating the progress of a event. If the culminating point of (66) is that John (or his friends) are under the table, how can we use this information to derive a scale for measuring the progess of the accomplishment. Similarly, we predict that in $(65 \mathrm{a} / \mathrm{b})$ the progress of the dancing event is measured differently in each case. In (65a) it is measured straighforwardly by which parts of the path denoted by out of the room are used by which parts of the event. In (65b), the incremental argument is not given by the PP, but by John, and thus the progress of the event should be calculated by measuring what happened to John. Presumably there are restrictions on the kinds of ways in which in entity like John can be involved in the measuring of the progress of an event, and these may account for restrictions on what APs can be used as resultative predicates, as demonstrated, for example in the contrast sing himself hoarse vs * sing himself famous, or in the minimal contrasts wipe the table clean/*wipe the table dirty. I would hope that a more detailed study of the nature of incrementality and the functions which allow us to measure event progress will allow us to gain more understanding of these issues. 


\section{References}

Andrews, Avery (1982): A Note on the Constituent Structure of Adverbials and Auxiliaries. Linguistic Inquiry 13, 313-317.

Carrier, Jill. and Janet Randall (1992): The Arguement Structure and Syntactic Structure of Resultatives. Linguistic Inquiry 23, 173-234.

Davidson, Donald (1967): The Logical Form of Action Sentences. In N. Rescher (ed.) The Logic of Decision and Action. Pittsburgh; Pa, University of Pittsburgh Press.

Dowty, David (1979): Word Meaning and Montague Grammar. Dordrecht: Kluwer.

- (1982): Grammatical Relations and Montague Grammar. In P. Jacobson and G.K.Pullum (eds.) The Nature of Syntactic Representation. Dordrecht: Kluwer

(1991): Thematic Proto-Roles and Argument Selection. Language 67, 546-619. Greenberg, Yael (1998): An Overt Syntactic Marker for Genericity in Hebrew. In S. Rothstein (ed.) Events and Grammar. Dordrecht: Kluwer

Halliday, Michael (1967): Notes on Transitivity and Theme in English, Part I. Journal of Linguistics 3, $37-81$.

Higginbotham, James (1985): On Semantics. Linguistic Inquiry 16, 547-593.

Hoekstra, Teun (1988): Small Clause Results. Lingua 74, 101-139.

Kratzer, Angelika (1995): Stage and Individual Level Predicates. In G. Carlson and F. Pelletier (eds.) The Generic Book, Chicago: Chicago University Press.

Krifka, Manfred (1992): Thematic Relations as Links between Nominal Reference and Temporal Constitution. In I.Sag and A Szabolsci (eds.) Lexical Matters. Stanford: CSLI

- (1998): The Origins of Telicity. In S. Rothstein (ed.) Events and Grammar. Dordrecht: Kluwer.

Landman, Fred (in press). Events and Plurality: The Jerusalem Lectures. Dordrecht: Kluwer.

Lasersohn, Peter (1992): Generalized Conjunction and Temporal Modification. Linguistics and Philosophy 15/4, 381-410.

Levin, Beth and Malka Rappaport Hovav (1995): Unaccusativity: At the Syntax-Lexical Semantics Interface. Cambridge, Mass: MIT Press.

- (1999): Two Structures for Compositionally Derived Events. In Proceedings of SALT IX.

Parsons, Terry (1990): Events in the Semantics of English. Cambridge, Mass: MIT Press.

Rothstein, Susan (1983): The Syntactic Forms of Predication. Ph.D. dissertation, MIT, Cambridge, Mass.

- (1992): Case and NP Licensing. Natural Language and Linguistic Theory 10. 119-139.

- (1999) Fine-grained Structure in the Eventuality Domain: The Semantics of Predicate Adjective Phrases and Be. Natural Language Semantics 7, 37-420.

- $\quad$ (in press): Predicates and their Subjects. Dordrecht: Kluwer.

- $\quad$ (in progress) Resultatives and Incremental Themes.

Rappaport Hovav, Malka and Beth Levin (1999): A Reevaluation of the Direct Object Restriction on English Resultatives. Manuscript, Bar-Ilan University and Stanford.

Simpson, Jane (1983): Resultatives. In L. Levin, M. Rappaport and A. Zaenen (eds.) Papers in LexicalFunctional Grammar. Bloomington, Indiana: Indiana University Linguistics Club.

Tenny, Carol (1987): Grammaticalizing Aspect and Affectedness. Ph.D. dissertation, MIT, Cambridge, Mass.

- (1994): Aspectual Roles and the Syntax-Semantics Interface. Dordrecht: Kluwer.

Verspoor, C.M. (1997): Contextually Dependent Lexical Semantics. Ph.D. dissertation, University of Edinburgh, Edinburgh, UK.

Wechsler, Stephen (1997): Resultative Predicates and Control. Texas Linguistics Forum 38, 307-321.

Williams, Edwin (1980): Predication. Linguistic Inquiry 11, 203-238. 